\title{
The utility of a patient robot in orthodontic practice
}

\author{
Katsuyoshi Futaki*, Tetsutaro Yamaguchi, Kousyu Katayama, Ayumi Kurihara, Wakana Yanagisawa, Ayako Yagi, Mutsuko Nakayama,
} Noriko Maruyama and Koutaro Maki

Department of Orthodontics, School of Dentistry, Showa University, 2-1-1 Kitasenzoku, Ota-ku, Tokyo 145-8515, Japan

\begin{abstract}
Objectives: Simulation education close to actual practice is desirable to learn clinical skills and risk management. The usefulness of a patient robot for orthodontic bonding practice was investigated in this study from June 2013 to August 2013.

Methods: Nine subjects participated in training using a mannequin and the patient robot, a lecture, and mutual training. The following items were analyzed: A. examiner's score, B. bonding time, C. bracket mounting position, and D. questionnaire results.

Results: When training using the patient robot was performed twice on the same day, the examiner's score rose and bonding time decreased. The examiner's score did not decrease after a 14-day interval. In contrast, when training using the patient robot was performed only once followed by a 14-day interval, the examiner's score markedly decreased Bracket heights of 32 and 35 were significantly lower, increasing deviation from the target value, in the training using the patient robot than those when using a mannequin. When performance of the training using the patient robot was compared between before and after the lecture and mutual training, the mean examiner's score in all subjects decreased and the bonding time increased after the lecture and mutual training. No significant difference was noted in the bracket mounting position.
\end{abstract}

Conclusions: The educational effect is markedly influenced by feedback immediately after training and iterative learning. It was clarified that training using the patient robot is more difficult than training using a mannequin. It was suggested that a patient robot is useful in orthodontic bonding practice.

\section{The value of written history}

Dentists can provide high-quality treatment to patients through gaining a lot of experience, for which it is necessary to accumulate experience before starting actual clinical practice. In addition, objective accurate evaluation of clinical skills and risk management is important [1]. To overcome these problems, simulation has been widely introduced as an educational tool in dentistry [2-6].

We developed a patient robot. The media globally have focused on patient robots, which have been introduced into dental schools worldwide. Simulation education may become the best tool for providing a lot of experience to dentists. Tanzawa et al. reported that clinical simulation training using a patient robot was effective to learn cavity preparation and how to deal with medical emergencies $[7,8]$. Bracket mounting position has a marked influence on the orthodontic treatment progress. But orthodontic bonding practice is performed only by the mannequin who doesn't move and the jaw model which has no lips and cheek mucous membranes at present. The objectives of this study were to clarify the educational effects of educational tools for orthodontic bonding practice and to investigate the usefulness of the patient robot.

\section{Materials and methods}

\section{Development of the patient robot}

This study has been exempted from Ethical Approval. Informed consent was obtained from the subjects. The patient robot attained a better appearance with practical use by improving the face mask and oral mucous membrane (Figures 1A and 1B). Powered by an electric motor, the neck turn becomes smoother, like in humans. The patient robot performed autonomic moves of the eyelids, eyeballs, jaw, tongue and neck to simulate a living patient. The dentition model was developed in cooperation with a collaborator and the patient robot was prepared so as to have 'Skeletal Cl.I, Angle Cl.I with crowding and a narrow upper arch' (Figure 1C).

\section{Subjects}

Five dentists 2 years after graduation and 4 residents one year after graduation (9 subjects in total) participated in this study. They had never performed orthodontic bonding in a patient robot or a real patient before the orthodontic bonding practice in this study.

\section{Design and implementation}

Using a conventional mannequin and the patient robot, training of bonding orthodontic brackets to 5 teeth (31-35) was performed (Figures 1D and 1E). The practice time was unlimited and the trainees completed the task (Table 1). The trainees were divided into a control group comprised of 5 subjects (Group C) and a patient robot group comprised of 4 subjects (Group R). The frequency of using the patient robot differed between the 2 groups (Table 1). Group C performed the training using a mannequin twice and then using the patient robot once. Group R performed the training using a mannequin once

Correspondence to: Katsuyoshi Futaki, Research Associate, Department of Orthodontics, School of Dentistry, Showa University, 2-1-1 Kitasenzoku, Otaku, Tokyo 145-8515, Japan, Tel: +81-3-3787-1151; Fax: +81-3-3784-6641; E-mail: futaki@dent.showa-u.ac.jp

Key words: dental education, orthodontic practice, patient robot, simulation Received: March 31, 2016; Accepted: April 22, 2016; Published: April 25, 2016 


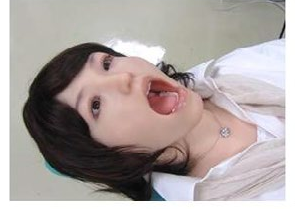

A

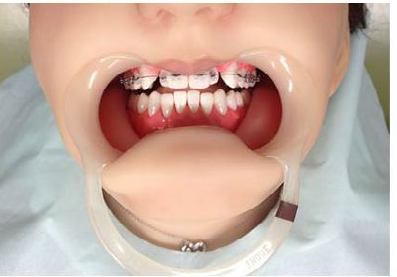

D

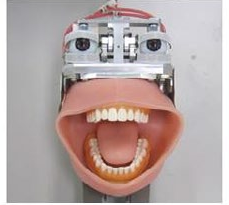

B

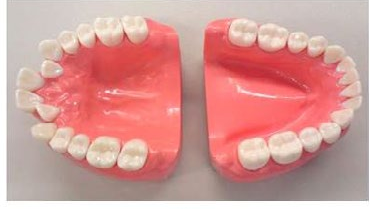

C

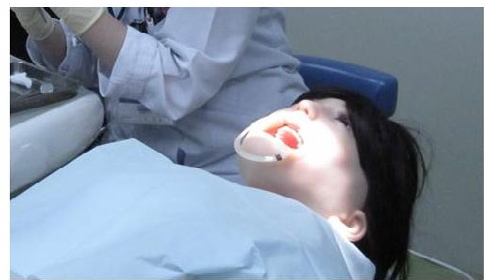

$E$
Figure 1. (A) Patient robot (external appearance), (B) Patient robot (internal structure), (C) Dentition model (D), Patient robot (attached with an angle wider) (E), Bonding to patient robot.

Table 1. Attach brackets to the left lower 1-5 at the positions specified below. Etching was already applied.

\begin{tabular}{|c|c|c|c|c|c|}
\hline & $\begin{array}{c}31 \\
\text { (central } \\
\text { incisor) }\end{array}$ & $\begin{array}{c}\mathbf{3 2} \\
\text { (lateral } \\
\text { incisor) }\end{array}$ & $\begin{array}{c}\text { 33 } \\
\text { (canine) }\end{array}$ & $\begin{array}{c}\mathbf{3 4} \\
\text { (first premolar } \\
\text { tooth) }\end{array}$ & $\begin{array}{c}\mathbf{3 5} \\
\text { (Second premolar } \\
\text { tooth) }\end{array}$ \\
\hline $\begin{array}{c}\text { bracket } \\
\text { height }\end{array}$ & $3.5 \mathrm{~mm}$ & $3.5 \mathrm{~mm}$ & $4.5 \mathrm{~mm}$ & $4.0 \mathrm{~mm}$ & $4.0 \mathrm{~mm}$ \\
\hline $\begin{array}{c}\text { bracket } \\
\text { angulation }\end{array}$ & $0^{\circ}$ & $0^{\circ}$ & $5^{\circ}$ & $0^{\circ}$ & $0^{\circ}$ \\
\hline
\end{tabular}

Table 2. Time schedule of training (differences between Groups $\mathrm{C}$ and R).

\begin{tabular}{|c|c|c|}
\hline & Group C & Group R \\
\hline $1^{\text {st }}$ & mannequins & mannequins \\
\hline $2^{\text {nd }}$ & mannequins & patient robot \\
\hline $3^{\text {rd }}$ & patient robot & patient robot \\
\hline \multicolumn{3}{|c|}{ Lecture on orthodontic bonding/mutual training } \\
\hline $4^{\text {th }}$ & patient robot & patient robot \\
8
\end{tabular}

and then using the patient robot twice. These were performed on the same day. After 6 days, both groups attended a lecture on orthodontic bonding and mutual training. Eight days later, both groups performed the training using the patient robot once (Table 2).

\section{Analyzed items}

A. Examiner's score: Two raters assessed the performance of the subjects using an evaluation sheet (Table 3 ). The scores were compared between Groups C and R.

B. Bonding time: The time to the completion of bonding from the initiation of training was measured. The time for observing the task was not included. The times were compared between Groups C and R.

C. Bracket position: Each tooth was scanned and analyzed using a cavity/abutment preparation grading system, Fair Grader 100 (NISSIN DENTAL PRODUCTS Inc., Kyoto, Japan), and 3-dimensional images of the bracket-mounted teeth were constructed. This system projects a $650-\mathrm{nm}$ semiconductor laser to a rotating tooth model and receives reflected light using a CMOS sensor. At the same time, 2 rotary encoders detect the position of the light source and angle of the tooth model and construct a 3-dimensional image. The bracket angulation, deviation of the center of the bracket, and bracket height were measured in the 3-dimensional image (Figure 2).
Each measurement was performed 3 times and the mean was calculated. All measurements were performed by the same operator to avoid inter-operator measurement errors. For statistical analysis, Student's t-test, Welch's t-test, and the Mann-Whitney test were used. The results were not compared between Groups C and R, and the 2 groups were combined in the analysis. The results of the 1st to 3rd training sessions using a mannequin and the patient robot were compared with those of the 4th training session using the patient robot after a lecture on orthodontic bonding and mutual training.

D. Dentist questionnaire (Table S1): Immediately after completion of the orthodontic bonding practice, all trainees completed a questionnaire. They were asked to rate each item on a scale from one to five (where $1=$ poor and $5=$ excellent).

Table 3. Examiner's score sheet.

\begin{tabular}{|c|c|}
\hline & $\begin{array}{l}\text { Checklist } \\
\text { Score }\end{array}$ \\
\hline a. & $\begin{array}{l}\text { Explanation to the patient. } \\
1: \text { Could be explained } \\
0: \text { Could not be }\end{array}$ \\
\hline b. & $\begin{array}{l}\text { Confirmation of the oral situation before treatment. } \\
1: \text { Could be confirmed } \\
0: \text { Could not be }\end{array}$ \\
\hline c. & $\begin{array}{l}\text { Selection of correct tools } \\
1: \text { Could be selected } \\
0: \text { Could not be }\end{array}$ \\
\hline d. & $\begin{array}{l}\text { Were tools appropriately used? } \\
1: \text { Correct tools were used. } \\
0: \text { Were not }\end{array}$ \\
\hline e. & $\begin{array}{l}\text { Was treatment carefully performed? } \\
1: \text { Treatment was carefully performed. } \\
0: \text { Was not }\end{array}$ \\
\hline f. & $\begin{array}{l}\text { Were tools/devices used roughly placed? } \\
1: \text { Tools were carefully placed. } \\
0: \text { Were not }\end{array}$ \\
\hline g. & $\begin{array}{l}\text { Change the direction of the patient's neck position. } \\
1: \text { Could be changed } \\
0: \text { Could not be }\end{array}$ \\
\hline h. & $\begin{array}{l}\text { Position of the operator. } \\
1: \text { Appropriate (position of 11:00 to } 12: 00 \text { ) } \\
0: \text { Not appropriate }\end{array}$ \\
\hline i. & $\begin{array}{l}\text { Attention to cleanliness. } \\
1: \text { Could be considered } \\
0: \text { Could not be }\end{array}$ \\
\hline $\mathrm{j}$. & $\begin{array}{l}\text { Attention to safety. } \\
1: \text { Could be considered } \\
0: \text { Could not be }\end{array}$ \\
\hline k. & $\begin{array}{l}\text { Attention to patient's pain and discomfort. } \\
1 \text { : Could be considered } \\
0: \text { Could not be }\end{array}$ \\
\hline 1. & $\begin{array}{l}\text { Tools and devices should not be passed over patient's head. } \\
1 \text { : Treatment could be performed without passing tools and devices over patient's head. } \\
0 \text { : Could not be. }\end{array}$ \\
\hline
\end{tabular}
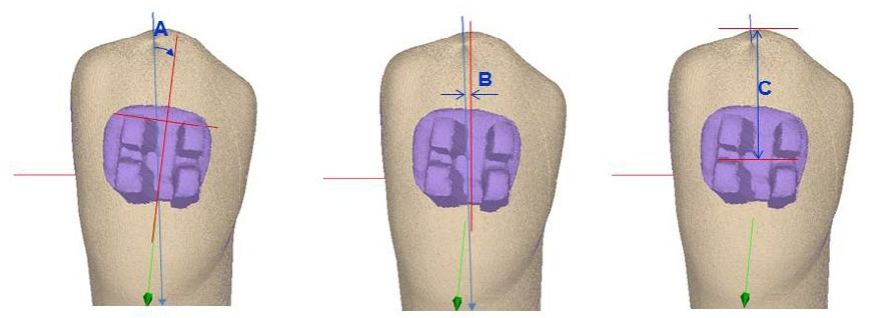

Figure 2. (A) Angulation, (B) measurement of deviation of the bracket center, (C) bracket height. 

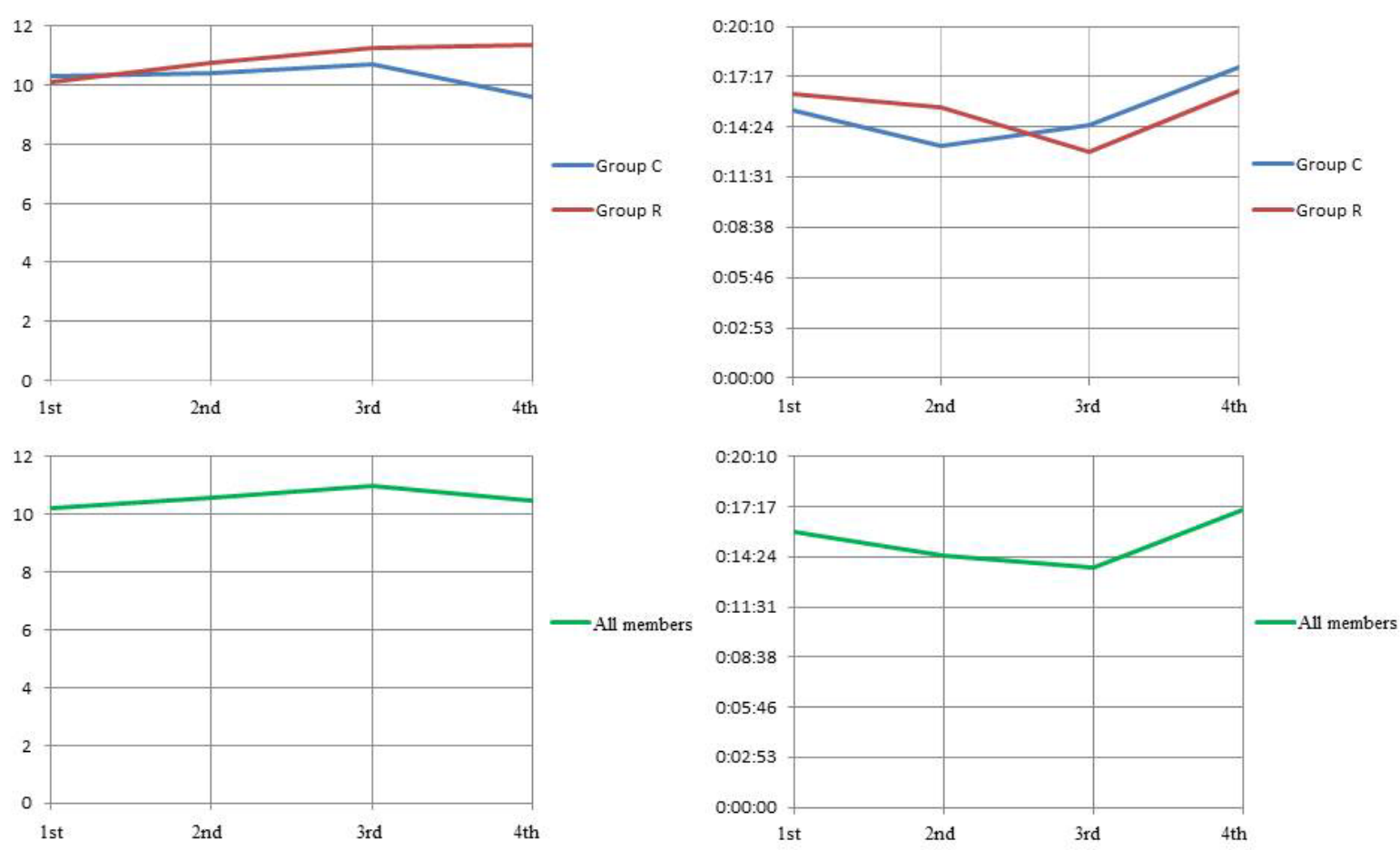

A

B

Figure 3. (A) Examiner's score, (B) Bonding time

\section{Results}

A. Examiner's score: On comparison between Groups R and C, only the score of the 1st training session was lower in Group R than in $\mathrm{C}$, and those of the 2nd to 4th training sessions were higher in Group $\mathrm{R}$ than in $\mathrm{C}$. The score gradually rose with the 4 training sessions in Group R, whereas it gradually rose until the 3rd training session but markedly decreased in the 4th training session in Group C. The score decreased in 4 evaluated items: 'changing the direction of the patient's neck', 'operator's position', 'attention to safety', and 'attention to the patient's pain and discomfort'. The scores markedly rose in the 1st to 3rd training sessions in Group R compared with those in Group C.

The mean in all subjects gradually rose in the 1st to 3rd training sessions and then decreased in the 4 th one (Figure $3 \mathrm{~A}$ ).

B. Bonding time (Figure 3B): On comparison between Groups $\mathrm{R}$ and $\mathrm{C}$, the bonding time was longer in Group $\mathrm{R}$ than in $\mathrm{C}$ in the 1st and 2nd training sessions. It was shorter in the 2nd than in the 1 st training session in both Groups R and C, and the change was larger in Group C than in R. In the 3rd and 4th training sessions, the time was shorter in Group $\mathrm{R}$ than in C. It was shorter in the 3rd than in the 2nd training session in Group R, whereas it was longer in the 3rd than in the 2nd training session in Group C. The time was markedly prolonged in the 4th than in the 3rd training session in both groups.

The mean in all subjects gradually decreased from the 1st to 3rd training session and was then prolonged in the 4 th one. When practicing continuously using the same one (patient robot or mannequin) on the same day, the time was shortest and the back was both groups as a result of the bonding time.

\section{Bracket position}

A) Bracket angulation:

$\operatorname{ATAN}(\mathrm{E} 3 / \mathrm{C} 3)^{\star} 180 / \mathrm{PI}()$

[ATAN] The arc tangent of the value of trigonometric function was determined. The determined value was a radian within the range from $-\mathrm{PI} / 2$ to $\mathrm{PI} / 2$.

[E3] Distance on the Z-axis between 2 points

[C3] Distance on the $\mathrm{X}$-axis between 2 points

$\left[{ }^{*} 180 / \mathrm{PI}()\right]$ The value is presented as an angle because ATAN is a radian.

No significant difference was noted in any tooth.

\section{B) Deviation of the bracket center}

$(\mathrm{ABS}(\mathrm{C} 3)-\mathrm{ABS}(\mathrm{E} 3)) / 2$

[ABS(C3)] The absolute value of the distance between the left sides of the tooth model and bracket was determined.

[ABS(E3)] The absolute value of the distance between the right sides of the tooth model and bracket was determined.

No significant difference was noted in any tooth.

\section{C) Bracket height}

Significant differences were noted in the bracket heights of 32 and 35 between the training sessions using a mannequin and the patient robot in the 1st to 3rd training sessions. For statistical analysis, Welch's and Student's t-tests $(\mathrm{P}<0.05$ each) were used for 32 and 35 , 
respectively. The mean height was lower, increasing deviation from the target value, in the training using the patient robot than in that using a mannequin in both 32 and 35 . No significant difference was noted in either 32 or 35 between the heights after the 1st to 3 rd training sessions using a mannequin and that after the 4 th training session using the patient robot performed after the lecture on orthodontic bonding and mutual training. Similarly, no significant difference was noted between the heights after the 1st to 3rd training sessions using the patient robot and that after the 4 th training session using the patient robot performed after the lecture on orthodontic bonding and mutual training.

No significant difference was noted in 31, 33, or 34.

\section{Dentist responses to the robot patient (Table S2)}

No item was scored as 1 or 2. The score of 'reproducibility of conversation' was the lowest and the mean was 3.89. Two, 4 , and 3 subjects rated it 5,4 , and 3 , respectively. This was due to little variation of speech. The mean score was 4 or higher in all other items, and $78 \%$ of the subjects evaluated the reproducibility of the oral cavity and tongue as 'excellent' and $89 \%$ evaluated the patient robot as 'very effective'. Regarding the reason for high evaluation, they commented that 'training in consideration of pain and discomfort is possible', 'there is a sense of reality because it has a whole body, not just a head', and 'it is more like a human than phantoms because movement cannot be predicted'. Regarding reproducibility, the lips, tongue, and buccal mucosa were included in regions considered well reproduced as well as regions that need to be improved. There was also a comment that the patient robot is not effective because it is not scary if I think that neither the mannequin nor the patient robot is a human'.

\section{Discussion}

The mean examiner's score in all subjects gradually rose from the 1st to 3rd training sessions and then decreased after the 4th one, and the mean bonding time in all subjects gradually decreased from the 1st to 3rd training session and was then prolonged in the 4th one, suggesting that the educational effect on acquiring orthodontic bracket bonding techniques was markedly influenced by feedback immediately after training and iterative learning.

In Group R, the examiner's score gradually rose with the 4 training sessions, clarifying that the effect of training using the patient robot repeated twice on the same day persisted for 14 days, that is, iterative training using the patient robot twice or more on the same day may be more effective, and it was suggested that the patient robot is effective in orthodontic bonding practice.

Bracket height measurement clarified that the training using the patient robot was more difficult than that using a mannequin. The deviations from the target values in 32 and 35 were larger in the training using the patient robot than using a mannequin, and this may have been due to difficulty in excluding the lips and buccal mucosa that inclined the boon gauge, resulting in a low bracket height. Moreover, no progress in the skill of bracket positioning was noted throughout the 4 training sessions. This was expected because orthodontic bracket bonding techniques cannot be acquired by only a few practices. Since the proficiency level may have varied among the subjects, it is difficult to compare the improvement of bracket mounting position simply based on the mean or significance of differences.

When the performance of the training using the patient robot was compared between before and after the lecture and mutual training, the mean examiner's score in all subjects decreased, the bonding time was prolonged, and no significant difference was noted in the bracket mounting position after the lecture and mutual training, suggesting that the lecture and mutual training have little immediate effect on acquiring orthodontic bracket bonding techniques.

In the dentist questionnaire, $78 \%$ of the subjects rated the reproducibility of the oral cavity and tongue 'excellent', and $89 \%$ rated the patient robot 'very effective'. The lips, tongue, and buccal mucosa were included in regions considered well reproduced as well as regions that need to be improved, clarifying the participants' need for high reproducibility of the lips, tongue, and buccal mucosa. 'Little variation of speech' was included in the comments concerning points to be improved and ineffective features. Improvement of the reproducibility of the lips, tongue, and buccal mucosa and an increase in variation of conversation are future tasks. It was also commented that the patient robot is not effective because it is not scary if I think that neither the mannequin nor the patient robot is a human'. Although this is a problem with the students, not with the training, we have to make efforts to provide training close to reality so that students feel that they are treating a real patient.

\section{Conclusion}

It was suggested that the educational effect is markedly influenced by immediate feedback received after training and iterative learning as a result of the examiner's score and the bonding time. It was clarified that training using the patient robot is more difficult than training using a mannequin as a result of the bracket position. It was suggested that the patient robot is useful in orthodontic bonding practice as a result of the dentist questionnaire. It's because a patient robot got the value of more than 4.67 in three questions. Three questions are "Did your consciousness of safety for patients increase after experiencing unexpected movement of this patient robot?", "Do you think that training using this patient robot is more effective than training using conventional mannequins?" and "Was your interest in dental treatment (clinical) increased by this training using the patient robot?".

\section{Acknowledgements}

The authors are grateful to Mr. Yoichi Takamoto, Mr. Yusuke Ishii, Mr. Kazunori Hatasako, and Ms. Mariko Ishikawa of Tmusk Co. Ltd. for the development of the robot patient. We also thank Mr. Masato Yamamoto, Mr. Ryousuke Oofuku, and Ms. Kanae Sawamura of NISSIN DENTAL PRODUCTS Inc. for the development of Fair Grader 100. This study was partially supported by a grant from the Ministry of Education, Culture, Science, Sports and Technology, Japan.

\section{References}

1. Mossey PA, Newton JP, Stirrups DR (2001) Scope of the OSCE in the assessment of clinical skill in dentistry. Br Dent J 190: 323-326. [Crossref]

2. Buchanan JA (2001) Use of simulation technology in dental education. J Dent Educ 65: 1225-1231. [Crossref]

3. Buchanan JA (2004) Experience with virtual reality-based technology in teaching restorative dental procedures. J Dent Educ 68: 1258-1265. [Crossref]

4. Imber S, Shapira G, Gordon M, Judes H, Metzger Z (2003) A virtual reality dental simulator predicts performance in an operative manikin course. Eur J Dent Educ 7: 160-163. [Crossref]

5. Wierinck ER, Puttemans V, Swinnen SP, van Steenberghe D (2007) Expert performance on a virtual reality simulation system. J Dent Educ 71: 759-766. [Crossref]

6. Issenberg SB, McGaghie WC, Hart IR, Mayer JW, Felner JM, et al. (1999) Simulation technology for health care professional skills training and assessment. JAMA 282: 861-866. [Crossref] 
7. Tanzawa T, Futaki K, Tani C, Hasegawa T, Yamamoto M, et al. (2012) Introduction of a robot patient into dental education. Eur J Dent Educ 16: e195-e199. [Crossref]
8. Tanzawa T, Futaki K, Kurabayashi H, Goto K, Yoshihama Y, et al. (2013) Medical emergency education using a robot patient in a dental setting. Eur J Dent Educ 17: e114-e119. [Crossref]

Copyright: (O2016 Futaki K. This is an open-access article distributed under the terms of the Creative Commons Attribution License, which permits unrestricted use, distribution, and reproduction in any medium, provided the original author and source are credited. 